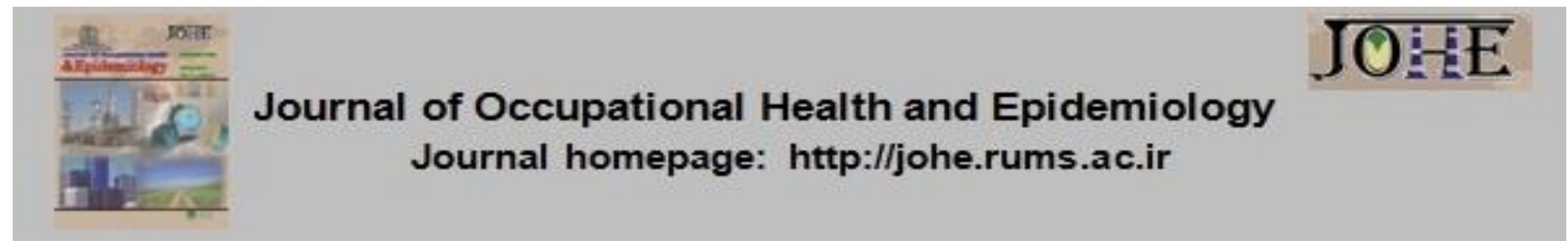

\title{
Knowledge, Attitude, and Perceived Threat of Butchers in Rafsanjan City concerning Brucellosis in 2020-2021
}

\author{
Leili Mazar ${ }^{1}$, Mostafa Nasirzadeh², Yaser Salim Abadi ${ }^{*}$ \\ 1. MSc Student, Student Research Committee, Rafsanjan University of Medical Sciences, Rafsanjan, Iran. \\ 2. Assistant Prof, Dept. of Health Education and Health Promotion, School of Health, Occupational Health and Safety Research \\ Center, NICICO, World Safety Organization and Rafsanjan University of Medical Sciences, Rafsanjan, Iran. \\ 3. Assistant Prof, Dept. of Health Services and Health Promotion, School of Health, Rafsanjan University of Medical Sciences, \\ Rafsanjan, Iran.
}

\section{Article Info}

* Corresponding author:

Yaser Salim Abadi,

E-mail:

yasernls@gmail.com

\section{Article history}

Received: May 2021

Accepted: Jun 2021

$10.52547 /$ johe. 10.2 .93

Print ISSN: 2251-8096 Online ISSN: 2252-0902

Peer review under responsibility of Journal of Occupational Health and

Epidemiology
Citation: Mazar L, Nasirzadeh M, Salim Abadi Y. Knowledge, Attitude, and Perceived Threat

of Butchers in Rafsanjan City concerning Brucellosis in 2020-2021. JOHE 2021; 10(2):93-8.

\section{Introduction}

Brucellosis is one of the common infectious diseases between humans and animals, which in addition to the economic losses caused by high mortality in domestic livestock, imposes many social problems on human communities [1]. Its causative agent is transmitted to humans through animals or their products infected. The most important routes of its transmission to humans include the consumption of raw milk and dairy products and contact with infected animal blood and secretion via wounds and scratches, as well as the inhalation of suspended particles in the air where animals are kept [2,3]. Most cases of Brucellosis are among people who deal with domestic animals, such as ranchers, butchers, and veterinarians; thus, it is considered an occupational disease [2]. Annually, more than 500,000 new cases of the disease are reported worldwide; however, this number is 10 to 25 times lower than the actual number in communities [4-6]. According to the results of studies, the seroprevalence of human Brucellosis in Iran is $1 \%$ 
to $2 \%$; also, the status of the disease in the country varies in different regions based on climatic conditions, access to pasteurized products, animal species, animal health level, and diagnostic tests $[7,8]$. In Kerman province, a moderate incidence of this disease has been shown [9]. Brucellosis occurs in acute, sub-acute, and chronic forms with nonspecific symptoms in humans, similar to those of the flu, including intermittent fever and chill, weakness, sweat, anorexia, joint pain, headache, and fatigue; therefore, it is difficult for physicians to diagnose it $[1,10,11]$. This disease is of great social and economic importance in humans and animals. Livestock disease affects the economy of livestock farmers and imposes high medical costs on the infected people [12]. Although the control and elimination of this disease in humans largely depends on vaccination, health measures, and its reduction in the livestock population, observing personal hygiene, preventing the spread, and performing preventive behaviors are the most significant points in protecting human health [8]. Studies conducted in Iran have shown that a lack of knowledge about Brucellosis transmission routes and preventive measures is one of the leading causes of the disease incidence [13]. Aminshokravi et al. reported a low level of knowledge and attitude of the villagers of Gilane Gharb city in this regard, making it difficult to tackle the disease [14]. In the study of Asadpour et al., the attitude of butchers in Rafsanjan city regarding Crimean-Congo Hemorrhagic Fever (CCHF) was favorable; however, their knowledge was unfavorable and moderate [15]. Due to the many problems related to the diagnosis of Brucellosis and its particular importance in animal agriculture, as well as considering that butchers are one of the high-risk groups and no study has been conducted on this medically-veterinary important disease up to date in Rafsanjan, the current survey aims at investigating the knowledge, attitude, and perceived threat of butchers in Rafsanjan city regarding Brucellosis.

\section{Materials and Methods}

The present descriptive correlational study was conducted to survey the knowledge, attitude, and perceived threat of butchers in Rafsanjan city concerning Brucellosis using a census method on 130 participants in 2020-2021.

The data collection tool was a standard questionnaire taken from the study of
Ramezankhani et al. [16], the validity of which was confirmed using the relevant experts' opinions. To measure the reliability, Cronbach's alpha method for questions of knowledge, attitude, and perceived threat was calculated at $0.86 \%, 0.85 \%$, and $0.55 \%$, respectively. The questionnaires were completed in the workplace using a self-report method. The inclusion criteria were willing to participate in the study, filling the questionnaire completely, as well as having at least primary education, minimum of one year of work experience, and no history of febrile illness in the past. Moreover, the exclusion criterion was the unwillingness to cooperate. The first part of the questionnaire was related to demographic information (age, marital status, work experience, education level). The second part of the questionnaire (62 questions) was associated with the knowledge about Brucellosis, including symptoms, preventive measures, and transmission routes, on a 3-point Likert scale with "Yes," "No," and "I do not know." Score 2 was given to the correct answer, score 0 to the wrong answer, and score 1 to "I do not know." The scores of this part ranged from 0 to 124 . The third part of the questionnaire (20 questions) was related to attitude on a 5-point Likert scale, including definitely agree (score 5) to definitely disagree (score 1). The range of scores in this part was from 20 to 100 , reported as a percentage as well. The fourth part of the questionnaire (12 questions) was associated with the perceived threat on a 5-point Likert, similar to the attitude part. In this part, the scores ranged from 12 to 60 . This study was approved by the Vice-Chancellor for Research and Technology of Rafsanjan University of Medical Sciences with an ethics code: IR.RUMS.REC.1397.004.

Data analysis was performed by SPSS software version 20 using statistical tests of one-way ANOVA, Independent t-test, and Pearson correlation at a significance level of less than 0.05 .

\section{Results}

In the present study conducted to investigate the knowledge, attitude, and perceived threat of butchers in Rafsanjan city regarding Brucellosis, all butchers (130 people) participated. The mean age of the participants was $39.68 \pm 11.23$; also, 97 participants $(75.2 \%)$ were married, and 91 of them (70\%) had the highest education level (secondary school and diploma). The mean work experience was 17.85 years (maximum 40 years and minimum 1 year) (Table 1$)$. 
Table 1. The mean score of knowledge, attitude, and perceived threat in terms of butchers' demographic variables

\begin{tabular}{|c|c|c|c|c|c|}
\hline \multirow{2}{*}{ Variable } & \multirow{2}{*}{ Status } & \multirow{2}{*}{$N(P)$} & Knowledge & Attitude & Perceived Threat \\
\hline & & & $\mathrm{M} \pm \mathrm{SD}$ & $\mathrm{M} \pm \mathrm{SD}$ & $\mathrm{M} \pm \mathrm{SD}$ \\
\hline \multirow{4}{*}{ Age categories } & $15-24 y$ & $16(12.3)$ & $87.06 \pm 8.78$ & $78.66 \pm 7.93$ & $47.20 \pm 4.84$ \\
\hline & $25-44 y$ & $82(63.1)$ & $89.60 \pm 10.86$ & $79.48 \pm 12.2$ & $47.89 \pm 6.71$ \\
\hline & $45-64 y$ & $29(22.3)$ & $94.10 \pm 13.03$ & $75.24 \pm 11.85$ & $45.20 \pm 6.42$ \\
\hline & $>65 y$ & $3(2.3)$ & $83.00 \pm 2.00$ & $77.66 \pm 7.50$ & $44.33 \pm 2.88$ \\
\hline \multicolumn{3}{|c|}{ P-value of One-way ANOVA } & 0.043 & 0.419 & 0.234 \\
\hline \multirow{4}{*}{ Education } & Primary school & $32(24.6)$ & $87.71 \pm 12.29$ & $76.71 \pm 11.24$ & $45.68 \pm 6.52$ \\
\hline & $\begin{array}{c}\text { Secondory } \\
\text { school }\end{array}$ & $49(37.7)$ & $90.65 \pm 10.66$ & $79.83 \pm 12.20$ & $47.85 \pm 6.73$ \\
\hline & Diploma & $42(32.3)$ & $91.45 \pm 11.49$ & $79.29 \pm 10.61$ & $47.95 \pm 5.94$ \\
\hline & Academic & $7(5.3)$ & $85.28 \pm 9.32$ & $70.71 \pm 14.37$ & $43.71 \pm 5.99$ \\
\hline \multicolumn{3}{|c|}{ P-value of One-way ANOVA } & 0.342 & 0.197 & 0.184 \\
\hline \multirow{2}{*}{ Marital status } & Single & $32(24.8)$ & $86.37 \pm 10.15$ & $77.51 \pm 9.55$ & $46.83 \pm 5.88$ \\
\hline & Married & $97(75.2)$ & $91.08 \pm 11.53$ & $78.70 \pm 12.36$ & $47.19 \pm 6.68$ \\
\hline \multicolumn{3}{|c|}{ P-value of Independent t-test } & 0.042 & 0.621 & 0.790 \\
\hline \multirow{4}{*}{ Work experience } & $<10 y$ & $44(34.6)$ & $86.95 \pm 10.44$ & $77.76 \pm 10.10$ & $47.39 \pm 5.82$ \\
\hline & $11-20 y$ & $49(38.6)$ & $90.91 \pm 10.58$ & $80.59 \pm 13.27$ & $48.20 \pm 7.00$ \\
\hline & $21-30 y$ & $21(16.5)$ & $92.57 \pm 12.82$ & $79.19 \pm 11.30$ & $47.80 \pm 6.54$ \\
\hline & $>31 y$ & $13(10.2)$ & $92.61 \pm 14.6$ & $72.07 \pm 10.32$ & $41.38 \pm 3.84$ \\
\hline \multicolumn{3}{|c|}{ P-value of One-way ANOVA } & 0.158 & 0.130 & 0.007 \\
\hline
\end{tabular}

The mean score and standard deviation of butchers' knowledge, attitude, perceived threat concerning Brucellosis was $89.90 \pm 11.31$ (out of
124), $78.39 \pm 11.67$ (out of 100 ), and $47.12 \pm 6.45$ (out of 60 ), respectively (Table 2 ).

Table 2. Mean and standard deviation of knowledge, attitude, and perceived threat of butchers in Rafsanjan concerning Brucellosis

\begin{tabular}{lcccccccc}
\hline Variable & $\begin{array}{c}\text { Mean } \\
\text { score }\end{array}$ & $\begin{array}{c}\text { Standard } \\
\text { deviation }\end{array}$ & Out of & $\begin{array}{c}\text { Minimum } \\
\text { score }\end{array}$ & $\begin{array}{c}\text { Maximum } \\
\text { score }\end{array}$ & Mode & Median & Range \\
\hline Knowledge & 89.90 & 11.31 & 124 & 69.00 & 120.00 & 95.00 & 89.00 & 49.00 \\
\hline Attitude & 78.39 & 11.67 & 100 & 44.00 & 100.00 & 82.00 & 80.00 & 56.00 \\
\hline Perceived threat & 47.12 & 6.45 & 60 & 28.00 & 60.00 & 49.00 & 47.00 & 32.00 \\
\hline
\end{tabular}

Table 3 presents the correlation between the mean score of knowledge, attitude, and perceived threat of butchers in Rafsanjan city regarding Brucellosis. A positive and significant correlation was observed between the mean score of butchers' knowledge with attitude $(p<0.001, r=0.515)$ and perceived threat $(p<0.001, r=0.559)$ (Table 3$)$. In the current research, one-way ANOVA test showed a significant difference between the mean scores of butchers' knowledge in terms of age $(p=0.043)$; further, the LSD post-hoc test revealed a significant difference between the mean score of knowledge of subjects aged 15-24years and 45-64 years $(p=0.01)$. This finding indicates that butchers aged 45 to 64 years had the highest level of knowledge about Brucellosis. The mean score of knowledge of married and single butchers' about Brucellosis was different based on the One-way ANOVA statistical test; this difference was significant $(p=0.042)$, indicating that married butchers' had more information about Brucellosis. There was a significant correlation between perceived threat and work experience ( $p=0.007)$. The LSD post-hoc test showed a significant difference between the mean score of butchers' perceived threat and work experience with more than 31 years compared with other categories (less than 10 years, $p=0.003 ; 11-20$ years, $p=$ $0.001 ; 20-30$ years, $p=0.004)$. This result shows that with the increase in work experience, the perceived threat of butchers regarding Brucellosis also increased (Table 1).

Table 3. Correlation between the mean score of knowledge, attitude, and perceived threat of butchers in Rafsanjan city regarding Brucellosis

\begin{tabular}{cccc}
\hline Variable & Knowledge & Attitude & Perceived threat \\
\hline Knowledge & 1 & & \\
\hline Attitude & $0.515^{\star \star}$ & 1 & 1 \\
\hline Perceived threat & $0.559^{\star *}$ & $0.877^{\star *}$ & \\
\hline
\end{tabular}

** The level of less than 0.01 
Table 4 provides the educational priorities about knowledge, attitude, and perceived threat of butchers regarding Brucellosis. Therefore, the most important educational priority was "disease transmission through infected vegetables," "belief in death due to the disease," and "belief in disabilities caused by the disease" in relation to knowledge, attitude, and perceived threat, respectively.

Table 4. Educational priorities about knowledge, attitude, and perceived threat of butchers in Rafsanjan city regarding Brucellosis

\begin{tabular}{cllcc}
\hline \multirow{2}{*}{ Variable } & \multicolumn{1}{c}{ Educational needs } & $\begin{array}{c}\text { Mean } \\
\text { score* }\end{array}$ & $\begin{array}{c}\text { Standard } \\
\text { deviation }\end{array}$ & $\begin{array}{c}\text { Educational } \\
\text { priority }\end{array}$ \\
\hline \multirow{5}{*}{ Knowledge } & $\begin{array}{l}\text { Knowledge of the disease transmission through infected } \\
\text { vegetables }\end{array}$ & 0.31 & 0.660 & 1 \\
\cline { 2 - 5 } & $\begin{array}{l}\text { Knowledge of the disease transmission through infected animal } \\
\text { wool }\end{array}$ & 0.46 & 0.769 & 2 \\
\cline { 2 - 5 } & $\begin{array}{l}\text { Knowledge of the disease transmission through contaminated } \\
\text { water }\end{array}$ & 0.54 & 0.789 & 3 \\
\cline { 2 - 5 } & Knowledge of the disease transmission from human to human & 0.60 & 0.877 & 4 \\
\hline \multirow{3}{*}{ Attitude } & Belief in death due to the disease & 3.45 & 1.41 & 1 \\
\cline { 2 - 5 } & $\begin{array}{l}\text { Belief in disease prevention by keeping fresh cheese in salty } \\
\text { water for 3 months }\end{array}$ & 3.63 & 1.65 & 2 \\
\cline { 2 - 5 } & Belief in not consuming fresh colostrum for prevention & 3.64 & 1.39 & 3 \\
\cline { 2 - 5 } Perceived & Belief in boiling milk for 3 to 5 min for prevention & 3.79 & 1.21 & 4 \\
\cline { 2 - 5 } threat & Belief in consequence of disability caused by the disease & 3.14 & 1.40 & 1 \\
\cline { 2 - 5 } & Belief in social consequences (job loss) due to the disease & 3.22 & 1.41 & 2 \\
\cline { 2 - 5 } & Belief in the psychological consequences of the disease & 3.48 & 1.28 & 3 \\
\cline { 2 - 5 } & Belief in getting sick in the future & 3.60 & 1.28 & 4 \\
\hline
\end{tabular}

${ }^{*}$ In the knowledge section, the mean score is 2 , and in the attitude and perceived threat sections, the mean score is 5 .

\section{Discussion}

Brucellosis is one of the most common infectious diseases in Iran that has many social and economic consequences [11]. In the present study, the overall score related to the butchers' knowledge was 70.07 , the attitude score was 78 , and the perceived threat score was 78.33 out of 100. Accordingly, it can be concluded that knowledge, attitude, and perceived threat of the butchers of Rafsanjan city concerning Brucellosis is acceptable and desirable. The findings of the present study were in line with those of other studies among butchers regarding Brucellosis. For example, in the study conducted by Prabhakar et al. [17] to investigate awareness regarding Zoonotic diseases among butchers, $60 \%$ of them had an awareness of Zoonotic diseases, such as Brucellosis. Gorouhi et al. [18] performed a survey among butchers in Kerman city to evaluate their knowledge and attitude about CCHF and reported both to be very good. Musallam et al. [19] studied knowledge and attitude toward Brucellosis among livestock owners' in Jordan and indicated that the studied population was highly aware of Brucellosis. In the study conducted in Khash city by Shahnavazi et al. [12], the mean score of knowledge, perceived sensitivity, and perceived severity of ranchers concerning Brucellosis were higher than average [12]. In contrast, a poor level of awareness was found in Singh and Jindal's study, so that the knowledge and attitude of most butchers were very poor towards Zoonotic diseases [20]. Similarly, Cloete et al. showed poor knowledge among livestock farmers [21]; also, inadequate knowledge regarding Brucellosis was observed in a survey among cattle keepers [22].The reason for this difference in knowledge probably is due to the studied target groups. In the studies with a target group of butchers, there was a higher level of awareness about disease compared to other target groups, which can be attributed to the regular participation of butchers in training courses by relevant health organizations. In the current investigation, no significant difference was observed between the mean score of butchers' knowledge, attitude, and perceived threat toward education level. Prabhakar et al. showed that individuals' education level predicted their perceptions about Zoonotic diseases, risk factors, transmission routes, and their life cycle [17]. Also, Alizadeh-Siuki et al. reported that farmers with higher education had a positive attitude towards preventive behaviors of Brucellosis [23]. The two latter studies were in contrast with the present work. In the present study, no significant correlation was observed between the mean scores of knowledge and attitude with work experience. However, in Prabhakar et al., butchers with more work experience had a higher level of knowledge regarding Zoonotic diseases and could easily identify the infected carcass to control infectious disease outbreaks [17]. Asadpour et al. reported that butchers' knowledge about CCHF had a direct 
and significant relationship with work experience [15]. There was no significant correlation between the mean scores of knowledge and attitude of butchers with work experience; however, a significant correlation was observed between perceived threat with work experience so that butchers with more than 31 years of work experience had more perceived threat compared with other groups. In this study, knowledge had a positive and significant correlation with attitude and perceived threat. Such a positive and significant correlation was also observed in the study of Babaei et al. conducted among livestock farmers in Charaoymaq County about Brucellosis [24]. Therefore, informing the community about the disease, especially at-risk groups, such as livestock farmers and butchers, can significantly reduce its prevalence. One of the important factors in preventing or tackling various diseases is people's attitude towards them. If people have a negative attitude towards health issues or diseases and see themselves at risk, it will be easier to tackle them. In the present study, the attitude was at a desirable level; however, in Alemayehu et al., livestock farmers had a weak attitude towards Zoonotic diseases [25]. The concept of perceived threat includes perceived severity and sensitivity [26]. In the present research, the perceived threat score was acceptable. High perceived sensitivity indicates that if butchers consider themselves susceptible to Brucellosis, they will adopt preventive behaviors. Understanding the severity of the disease and its impact on the butchers and their family members can also increase the adoption of preventive behaviors among them. In Shahnavazi et al., the perceived severity score was 10 out of a maximum of 15 ; this construct was directly related to preventive behaviors [12]. Indeed, by raising knowledge of people about the consequences of the disease in communities and families, their perceived severity of the disease can be increased. Increasing knowledge about Brucellosis in high-risk occupational groups plays an important role in effectively controlling the disease [4]. In the present work, the most important educational need of butchers in the knowledge construct was to create knowledge of not transmitting the disease through infected vegetables. Therefore, evaluating individuals' general knowledge about various dimensions of the disease can be the basis for developing and implementing more efficient health education activities. The main educational need of butchers in attitude was to create "belief in the death due to the disease," and in perceived threat was to create "belief in consequence of disability caused by the disease" in them. Hence, health education interventions can be effective when individuals' beliefs and perceptions about the susceptibility to Brucellosis and the severity of its consequences are identified. The limitation of the current survey was the unwillingness of some butchers to participate in the study; therefore, to solve this problem, the researcher tried to emphasize the importance of research and the necessity of accurate answers to questions.

\section{Conclusion}

In general, the knowledge, attitude, and perceived threat of the butchers in Rafsanjan city regarding Brucellosis were all favorable; however, the awareness of different routes of Brucellosis transmission and belief in its related consequence needs to be upgraded among butchers. For this purpose, training workshops and educational courses can be held based on the butchers' educational needs identified according to prioritization. Therefore, communication and cooperation between health sectors, education sectors, butchers, and other relevant occupational groups are beneficial and necessary to improve the knowledge of butchers to effectively control Brucellosis.

\section{Acknowledgement}

This study is the result of a research project approved by the Vice-Chancellor for Research and Technology of Rafsanjan University of Medical Sciences with an ethics code: IR.RUMS.REC.1397.004.

\section{Conflict of interest: None declared.}

\section{References}

1. Dehnavi S, Sohrabi N, Zarei S, Afshari Safavi A, Afrasiabi B, Salimi K. Demographic characteristics, clinical signs and laboratory findings in Brucellosis hospitalized patients in Kermanshah. Journal of Clinical Research in Paramedical Sciences 2015; 3(4):e82123.

2. Hajari $A$, Shams $M$, Afroghi $S$, Fadaei $R$, Abaspoor Najafabadi.R. Brucellosis in Tiran \& Karvan: Study of the Disease in the Recent 10Year Period (2004-2013). Military Caring Sciences Journal 2016; 3(2):100-6.

3. Azizi A, Shams M, Seidkhani A, Hosseinzadeh M, Jalilian M, Havasi S. Evaluation of Health Education Program on Knowledge, Attitude, and Preventive Behaviors of Brucellosis among Villagers in Holilan, Iran. Scientific Journal of Ilam University of Medical Sciences2020; 28(4):47-53.

4. Zhang $N$, Zhou $H$, Huang DS, Guan P. Brucellosis awareness and knowledge in communities worldwide: A systematic review 
and meta-analysis of 79 observational studies. PLoS Negl Trop Dis 2019; 13(5): e0007366.

5. Mufinda FC, Boinas F, Nunes C. Prevalence and factors associated with human brucellosis in livestock professionals. Rev Saude Publica 2017; $51: 57$.

6. Azizi Mayvan F, Hashtarkhani S, Latifi M, Darrudi R, Hoseini B. Geographic disparities of brucellosis distribution in Neyshabur between 2014 and 2016: a cross-sectional study based on geographical information systems. Journal of Neyshabur University of Medical Sciences 2019; 7(4):53-64.

7. Farzadmehr MR, Ghorbani $M$, Sadeghi $M$, Mosavi Bazzaz SM. The Effect of Education based on the Health Belief Model in Reducing the Risk Factors of the Brucellosis in Torbat Haydariyeh. Journal of Torbat Heydariyeh University of Medical Sciences 2019; 6(4):4756.

8. Eskandari Z, Bashirian S, Barati M, Soltanian AR, Hazavehei SMM. The Effect of Educational Program Based on the Health Belief Model on Brucellosis Preventive Behaviors among Traditional Ranchers in Rural Areas of Hamadan Province. Journal of Education and Community Health 2017; 3(4):16-23.

9. Golshani M, Buozari S. A Review of Brucellosis in Iran: Epidemiology, Risk Factors, Diagnosis, Control, and Prevention. Iran Biomed J 2017; 21(6):349-59.

10. Amani $H$, Shams $H$, Matlabi $M$, Erfanpour $S$, Kamel Khodabandeh A. The Effect of Education Based on the Theory of Planned Behavior on Expression of Preventive Behaviors Concerned with Brucellosis in Farmers. Journal of Torbat Heydariyeh University of Medical Sciences 2020; 8(1):24-35.

11. Hashtarkhani S, Akbari M, Jarahi L, Etminani K. Epidemiological characteristics and trend of incidence of human brucellosis in Razavi Khorasan province. Medical Journal of Mashhad University of Medical Sciences 2016; 58(9):531-8.

12. Shahnavazi M, Masoudi G, Ansari-Moghadam A, Raeisy D, Khashei Varnamkhasti F. Preventive Behaviors of Brucellosis in Khash City Ranchers Based on Health Belief Model. Iranian Journal of Health Education and Health Promotion 2017; 4(4):281-8.

13. Rezaii H, Niknami S, Tavvafian SS, Karami Matin B. The effect of a designed educational program regarding brucellosis prevention on knowledge, attitude and preventive behaviors of rural females of Kermanshah, Iran. Payesh 2014; 13(1):91-9.

14. Aminshokravi $F$, Khanian $H R$, Hashemian $A H$. Effect of training on preventive behavior of brucellosis. Iranian Journal of Health Education and Health Promotion 2013; 1(3):15-22.

15. Asadpour M, Darehkordi M, Abdollahi SH, Salim Abadi Y. Knowledge, attitude and practice of butchers about Crimean-Congo hemorrhagic fever (CCHF) in Rafsanjan City in 2019. Journal of Jiroft University of Medical Sciences 2020; 7(3):440-9.

16. Ramezankhani A, Jahani $H$, Hatami $H$, Sharifzadeh $\mathrm{GH}$, Hosseini $\mathrm{SH}$. Determining the effect of intervention on the adoption of preventive behaviours of the brucellosis was based on the health belief model. Journal of North Khorasan University of Medical Sciences 2016; 8(1):33-45.

17. Naveen Prabhakar Z, Lokesh $M$, Saidaiah $M$, Sri Sai E. Awareness Regarding Zoonotic Diseases among the Butchers of Proddatur, Kadapa Dist. AP, India. Iranian Journal of Health Safety and Environment 2017; 4(2):72937.

18. Gorouhi MA, Ismaeil A, Afshar AA, Gohari, MA. Knowledge, attitude and practice towards crimean congo hemorrhagic fever (CCHF): A survey among butchers community in Kerman City. Journal of Entomological Research 2020; 44(3):495-500.

19. Musallam II, Abo-Shehada MN, Guitian J. Knowledge, Attitudes, and Practices Associated with Brucellosis in Livestock Owners in Jordan. Am J Trop Med Hyg 2015; 93(6):1148-55.

20. Singh AS, Jindal P. Awareness and practices among butchers of unorganized slaughter houses of Punjab regarding Zoonotic diseases. Res Environ Life Sci 2017; 10(10):824-7.

21. Cloete A, Gerstenberg C, Mayet N, Tempia S. Brucellosis knowledge, attitudes and practices of a South African communal cattle keeper group. Onderstepoort J Vet Res 2019; 86(1):e1e10.

22. Hussain S, Hussain A, Zia UuR, Naqvi SMR, Zahoor MY, Bilal M, et al. Knowledge, attitude, and practices associated with brucellosis among livestock owners and its public health impact in Punjab, Pakistan. Biologia 2021. doi:10.1007/s11756-021-00765-2

23. Alizadeh-Siuki H, Tehrani H, Gholian-Aval M, Ebrahimipour $\mathrm{H}$, Vahedian-Shahroodi $M$. Behavioral determinants of brucellosis incidence among stockbreeders and their family members in rural area based on PRECEDE model. J Edu Health Promot 2020; 9:166.

24. Babaei V, Babazadeh T, Kiani A, Garmaroodi G, Batebi A. The Role of Effective Factors in Preventive Behaviors of Brucellosis in Stockbreeder of Charaoymaq County: A Health Belief Model. Journal of Advanced Biomedical Sciences 2016; 5(4):470-8.

25. Alemayehu G, Mamo G, Desta H, Alemu B, Wieland $B$. Knowledge, attitude, and practices to zoonotic disease risks from livestock birth products among smallholder communities in Ethiopia. One Health 2021; 12:100223.

26. Glanz K, Rimer BK, Viswanath K. Health Behavior: Theory, Research, and Practice (Jossey-Bass Public Health). 5th ed. New York City, United States: Jossey-Bass; 2015. 